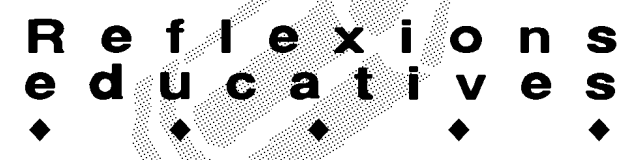

\title{
LA CULTURA FAMILIAR: UNA NOVA APROXIMACIÓ AL CONCEPTE DE FAMÍLIA
}

\author{
María del Pilar Zeledón Ruiz. Professora titular i investigadora del Departament d'Educació i de l'Institut \\ d'Investigació en Educació. Universitat de Costa Rica
}

\section{Introducció}

A tota producció humana hi ha la possibilitat de definir nous camins que contribueixin a una major clarificació del significat i de les implicacions dels constructes teòrics, i especialment pedagògics, que ens permetin comprendre la realitat social que ens envolta, en un esforç per trobar vies alternatives d'anàlisi i actuació educativa que tinguin una aportació a la reconstrucció dels fonaments de la humanitat. En aquest article s'intentarà una aproximació a una nova forma d'entendre la família des de la noció de cultura familiar, amb el propòsit que els lectors visualitzin l'entramada xarxa que hi ha a la dinàmica familiar i la seva ingerència en els processos formatius.

En aquest treball es presenten alguns dels resultats de la tesi doctoral, amb menció europea, titulada: $L a$ cultura familiar dentro de los procesos de configuración de la personalidad ética de los niños y niñas: hacia la construcción de una ciudadanía democrática. Aquesta investigació es desenvolupà en el marc del programa "Educació i Democràcia" del departament de Teoria i Història de l'Educació, de la Universitat de Barcelona, amb el suport de la Universitat de Glasgow (Escòcia), gràcies a la beca obtinguda a la Universitat de Costa Rica (Programa de Formación de Recursos Humanos en el exterior) i al suport de la Organización de Estados Iberoamericanos (OEI).

Des d'una perspectiva "hemenèutica" crítica, l'estudi va permetre les diferents veus que es conjuguen en l'apreciació de la realitat familiar dins d'una societat oberta i plural. Fou així com es va poder recollir, mitjançant el mètode Delphi, el criteri de vint-i-cinc experts de diferents disciplines (Filosofia, Sociologia, Psicologia, Pedagogia, Antropologia) i de nou universitats (set espanyoles i dues d'estrangeres), així com les consideracions de directores i mestres de parvulari. A aquesta població s'hi suma la veu de vint-i-cinc pares i mares de família, amb relats de la vida quotidiana i consultes sobre el model de la personalitat ètica, i de vint-i-sis nens de cinc i sis anys de dos centres educatius del districte d'Horta-Guinardó de Barcelona (CEIP Pau Casals i CEIP Els Pins), els quals compartiren les seves idees mitjançant el test de la "Figura Humana". Tots ells van ser els protagonistes d'aquest treball, aportant la seva reflexió i experiència.

A partir d'aquesta anàlisi es proposen pautes orientatives per als educadors, pares i mares de família, que els permetin contribuir a la formació ètica dels nens $i$ nenes, de tal manera que les futures generacions posseeixin eines competents per assolir societats més humanes $\mathrm{i}$ justes, on els ideals democràtics puguin trobar un terreny fèrtil on arrelar i consolidar-se.

En aquest treball es realitza un recorregut des de les aportacions més significatives al voltant del mot "cultura", tenint en compte diferents vessants: filosòfica, antropològica, psicològica, sociològica i pedagògica, atesa la seva complexitat i caràcter polisèmic, amb l'objectiu d'articular el seu sentit amb un altre terme, no menys polimorf $i$ transcendent, com és el concepte de "família". La complementarietat de les seves significacions ens ha permès arribar a una noció escassament assumida pel discurs acadèmic, que denominem "cultura familiar", com un terme que assumeix la seva pròpia identitat per desxifrar un univers de possibilitats de comprensió de la dinàmica humana, inserida en la quotidianitat de la realitat familiar i potenciadora d'una societat que aspira a consolidar els ideals democràtics, ideals amb els quals hem somiat durant segles.

Paral-lelament a la indagació bibliogràfica, ens ha semblat pertinent i necessari establir un "diàleg" entre aquells que assimilen i comprenen la realitat familiar, ètica i ciutadana, de diferents maneres; uns des de l'òptica més acadèmica i altres des de l'àmbit més quotidià. A partir de les seves aportacions, en qualitat d'actors directes d'aquest treball, hem assolit una major clarificació del fenomen estudiat, les seves possibilitats i limitacions, i s'han ratificat els resultats d'altres estudis que guarden una estreta relació amb alguns dels seus postulats. Sens dubte, els mateixos paradigmes i experiències vitals de cadascun dels participants han estat un insumo (insumo, en castellà, significa: conjunto de bienes empleados en la producción de otros bienes) fonamental en aquest treball.

Atesa la riquesa i amplitud de la informació recollida, no resulta fàcil concretar les idees més rellevants de cadascun dels grups consultats, ni de les fonts biblio- 


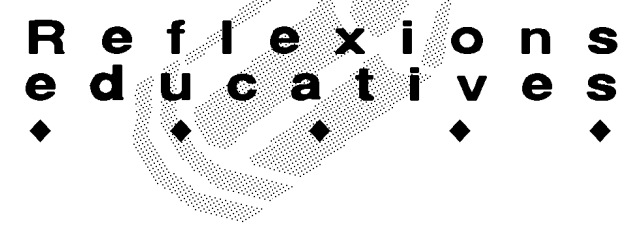

gràfiques que inspiraren la reflexió; no obstant això, en un esforç de síntesi farem una primera aproximació al concepte de "cultura familiar" i a les principals característiques d'aquesta.

\section{Aproximació al concepte cultura familiar}

La gran majoria dels especialistes (68\% experts, $58 \%$ directores i professores) consideraren que el terme "cultura familiar" és relativament nou en el discurs acadèmic i en ressaltaren la seva versatilitat, no només perquè ens permet aproximar-nos a una realitat complexa des d'una perspectiva d'alt nivell de significat, sinó també perquè afavoreix l'especificitat d'alguns processos d'anàlisi i interpretació, no sempre fàcils de comprendre.

Només el $32 \%$ dels experts consultats havien escoltat, llegit o utilitzat el mot en alguns dels seus treballs, la majoria d'ells usant-lo com a sinònim de la noció de família, context familiar, entorn familiar, entre d'altres. Alguns l'associaren a autors com Bordieu, Passeron, Thibon o Freire, encara que el seu tractament estava més relacionat amb la noció d'“habitus", "capital cultural" o "educació popular".

A l'intentar reunir els diferents elements a què van fer referència els especialistes consultats, així com les directores i professores, vàrem trobar reiteracions i convergències que ens han permès oferir, després de la seva anàlisi, una possibilitat d'aproximació a la noció de cultura familiar, mitjançant una sèrie de dimensions que mostren no només la singularitat i complexitat d'aquest escenari cultural, sinó també els seus abastos com a realitat sistèmica que es nodreix d'una sèrie d'elements, amb capacitat de modelació i transformació recíproca, en un procés dinàmic i humanitzador. Aquestes dimensions que proposem serien les següents:

a) Dimensió estructural. Fa referència a la distribució i ordre que presenta la família. Això significa que parlaríem del conjunt de persones que de manera quotidiana freqüenten un mateix espai físic. Ens interessaria saber el tipus de persones que hi ha: si hi ha present el pare, la mare i els fills, o més aviat la mare, l'avi i els fills; o només la parella. És a dir, quins de manera habitual freqüenten la llar, quines persones s'acosten a realitzar determinades activitats (mainadera, avis, fills, entre d'altres), qui hi és i amb qui, en aquest cas quines persones habiten aquell espai i amb qui el comparteixen, quin és l'objectiu de la seva presència i per quant de temps, on viuen.

b) Dimensió històrica. Hi inclouríem l'herència familiar, les tradicions derivades dels mateixos entorns familiars, les ensenyances i aprenentatges adquirits dels avantpassats (de manera directa o indi- recta), el bagatge de coneixements i experiències que s'han rebut i que es podran reviure de formes diverses segons les possibilitats que cadascú assumeixi en els seus projectes.

c) Dimensió quotidiana. Es considera el tipus d'escenari familiar que es té preparat, l'organització de l'espai (com estan distribuïdes les estances de la casa, qui les utilitza, de quina manera les fan servir i per a què, per quant temps), els objectes que es tenen (exemple: nombre de llibres que hi ha, de televisors que es tenen a disposició), la forma com es gestiona el temps i s'estructuren els horaris (nombre d'hores que es dediquen a veure la televisió, nombre d'hores que es dediquen a la lectura, a jugar...), l'organització de les activitats dins o fora de la llar, l'organització de les rutines diàries (esmorzar, neteja personal, vestuari, assistència a l'escola, activitats extraescolars), l'organització de l'alimentació (què es menja, quant es menja, com es menja, on es menja), la forma en la qual es construeix la vida quotidiana (si resulta estructurada o més aviat caòtica, si és o no previsible des de la perspectiva del nen o de l'adult).

d) Dimensió interactivo-comunicativa. Contempla la complexa xarxa de relacions i interaccions que es conjuguen en la cultura familiar i que està mitjançada pels mecanismes de comunicació que s'utilitzen, la presència d'un llenguatge propi, ja sigui verbal o no, els vincles afectius que s'estableixen, el tipus de trobades que es donen, la quantitat i qualitat del temps del qual es disposa per a aquestes trobades, les formes de moure's, les vinculacions a través dels objectes, les formes de violència, les conductes que s'observen, com es resolen els conflictes quotidians, les pràctiques educatives dels pares (autoritàries, permissives, democràtiques), com s'estimula els fills/es, el tipus d'escola on van, el tipus de persones amb les quals es relacionen, el tipus de llocs extrafamiliars als quals tenen accés, entre d'altres.

e) Dimensió semiòtica. Fa referència al sistema de significats que donen unitat a l'estructura familiar. És a dir, el que es pensa de la família, allò que no es té racionalitzat, el que es deriva de les seves produccions, els valors explícits o implícits que hi són presents (ex. igualtat, autonomia, diferència, diàleg, democràcia) així com el conjunt d'actituds, normes, hàbits, costums i creences presents a la dinàmica familiar on es viu. En aquesta dimensió podem recollir les diferents percepcions que els membres de la família mantenen en les relacions 


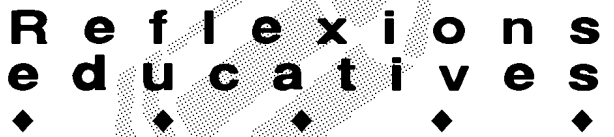

d'uns amb els altres, les motivacions que es confereixen a certs elements de la vida quotidiana que tenen un major protagonisme, la valoració de certes formes d'expressió o de comportament que manifesten els diferents membres de la família, les raons per les quals certes persones, animals o objectes són o no presents a la llar. En fi, tot allò que sens dubte aporta a la construcció de l'imaginari familiar.

f) Dimensió prospectiva. Les expectatives i ideals que nidifiquen dins la cultura familiar s'ubicarien en la dimensió prospectiva. La construcció personal i col-lectiva d'un projecte futur que planifica, desenvolupa i valora els objectius assolits o les limitacions enfrontades per buscar nous horitzons d'actuació, possibilitant el diàleg entre els actors, fomentant la creació de xarxes de col-laboració, afavorint el consens al voltant de les prioritats i la visió compartida del futur, així com propiciant el compromís entre els resultats obtinguts i els ob- jectius per aconseguir.

Aquestes dimensions interactuen en un procés cíclic que heretem, construïm i projectem des de la nostra cultura familiar, en la interconnexió del qual es configura la personalitat ètica de cadascun dels seus membres. En aquest treball destaca especialment la formació ètica del nen, de tal manera que pugui convertir-se en un agent transformador de la cultura general, sobre la base dels ideals democràtics, dels quals s'ha nodrit en els seus primers anys.

\section{Característiques de la cultura familiar}

L'aproximació que hem donat al concepte de cultura familiar ens permet identificar una sèrie de característiques que tot seguit es descriuen:

Realitat ecològico-sistèmica. La complexitat de la cultura familiar ens suggereix una anàlisi de la seva realitat dins d'un paradigma ecològico-sistèmic, on les relacions interpersonals es construeixen recíprocament dins de contextos d'influència que responen a processos

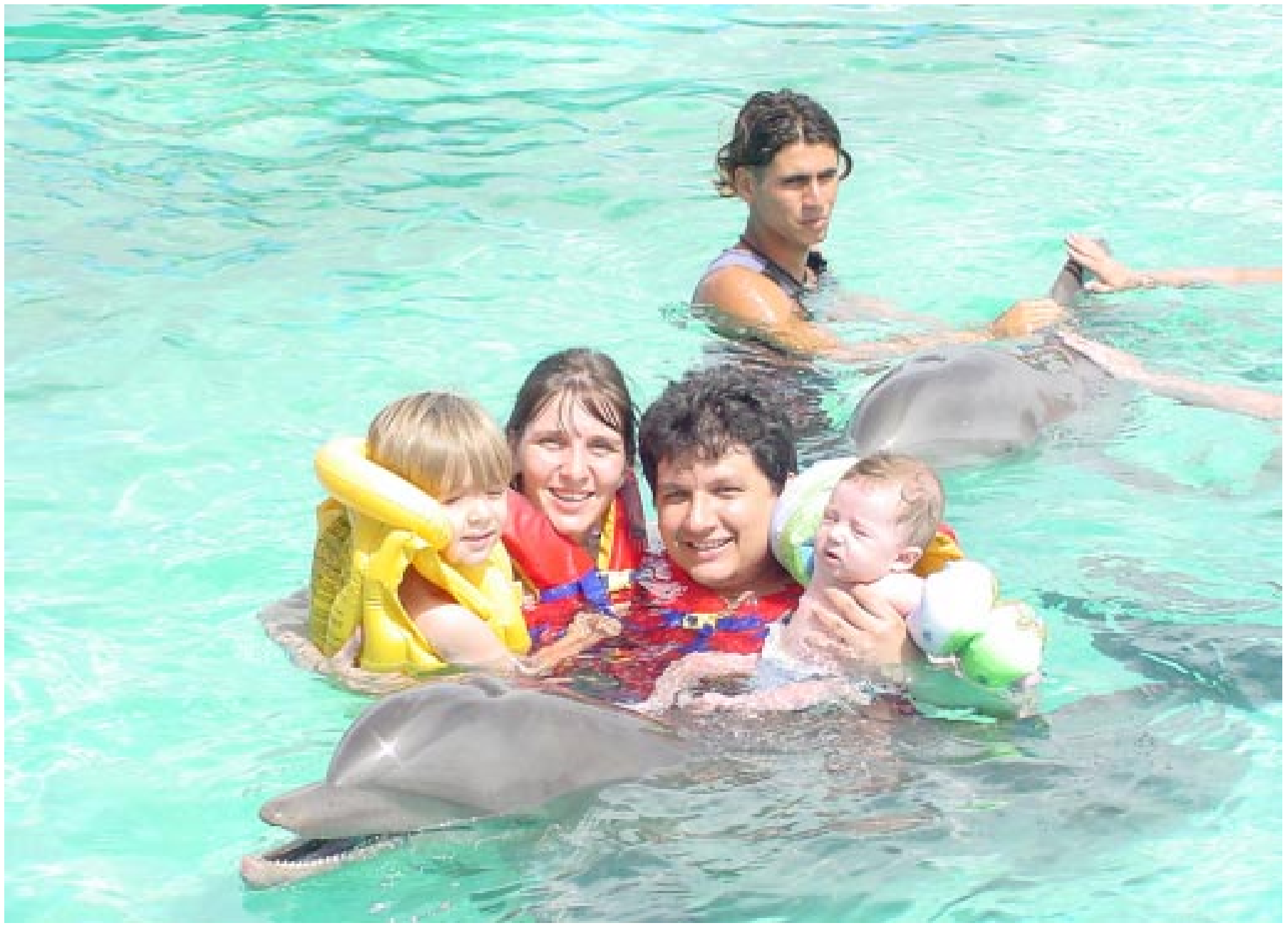




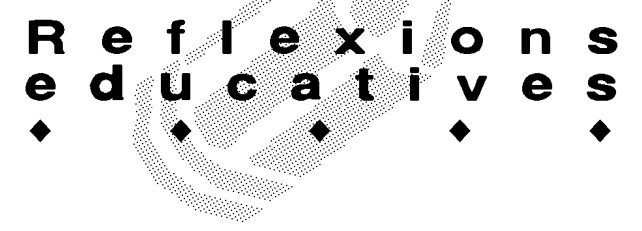

socials i històrics de canvi (PALACIOS i RODRI$\mathrm{GO}, 1998)$. Aquesta interdependència de les interaccions suposa que la qualitat d'una relació influeix i, al mateix temps, és influïda per la resta de les relacions (LEWIS i BROOKS-GUNN, 1979; BELSKY, 1980; MUSITU, 1994), sense perdre de vista la interconnexió d'aquesta dinàmica familiar amb les realitats extrafamiliars que la fan permeable, però que a la vegada aquella també les configura.

No fou fins a les acaballes de la dècada dels anys setanta i començament dels vuitanta quan les aportacions de Bertalanffy (1968) es van integrar plenament dins d'un model sistèmic de família. Es podria definir un sistema com un conjunt d'elements organitzats que conformen una malla de parts interdependents i coordinades i que funcionen com una unitat, sent necessari definir els contorns del sistema, els seus components, així com els seus propòsits i funcions en relació amb el centre d'atenció.

D'aquesta manera, diferents teòrics mantenen que els processos de relació a la família principalment són transaccionals (SAMEROFF i CHANDLER, 1975; RODRIGO i PALACIOS, 1998; LUJÁN, VANDEMEULEBROECKE i COLPIN, 2001). Als processos transaccionals, les persones mantenen canvis interns en el decurs de l'intercanvi amb els altres. Totes les parts del camp transaccional són interdependents i, cadascuna modifica la resta mitjançant un feedback circular, que es dóna al llarg del temps (SAMEROFF,1983).

Es podria afirmar que els fills, mitjançant les relacions recíproques amb els seus pares, contribueixen activament a construir o modelar els seus propis entorns de desenvolupament (LERNER, 1982). "Bondat d'ajustament" es denomina el model mitjançant el qual alguns autors sostenen que aquells fills les característiques dels quals permeten respondre satisfactòriament les demandes dels contextos en què es mouen, reben una resposta positiva i mostren un desenvolupament molt adaptable. Si succeeix el contrari, el cercle d'influències mútues produeix resultats negatius en el desenvolupament de la persona (THOMAS i CHESS, 1977).

\section{Espai d'encontre intergeneracional}

La quantitat de generacions que es poden fer presents dins d'una cultura familiar és variable i dependrà, en gran mesura, de l'estructura familiar que es consolidi. Generalment, s'estableixen vincles de tres generacions: avis, pares/mares i fills/es, encara que es poden trobar només dues (pares i fills, avis i néts) o més de tres (avis, pares, oncles, cosins i fills).

Cada generació aporta, des de la seva pròpia història i desenvolupament, una sèrie de components que ma- tisen l'atmosfera familiar. Des de la saviesa i paciència de l'avi/a fins a la ingenuïtat i espontaneïtat del nen/a, passant per la responsabilitat, afecte i compromís dels pares i mares. Tots aquests elements, que només es mencionen a títol d'exemple, poden estar presents en major o menor proporció en cadascuna d'aquestes generacions; no són exclusives, ni excloents, s'entreteixeixen en diferents interaccions que configuren la identitat d'aquella cultura familiar.

Aprendre a ser i aprendre a conviure són els pilars bàsics de l'educació del segle XXI, segons l'informe Delors (1996), i trobaran en la cultura familiar un terreny fèrtil per construir-se. La singularitat de cada generació afavoreix el desenvolupament del respecte i la tolerància, així com propicia una relació de trobada amb aquells que han viscut situacions històriques i culturals diferents, però que conflueixen, en un determinat moment, dins d'un context dinamitzador d'intercanvi de sabers, experiències, sentiments i expectatives.

Reconèixer i valorar aquesta aportació ens permet estendre ponts intergeneracionals que es converteixin en bastides de les futures descendències. Les generacions poden desenvolupar-se en espais d'actuació comuns compartint-los amb els seus coetanis, però a la vegada, poden obrir-se a la interacció amb altres que no ho són, en un procés d'enriquiment mutu, d'aprenentatge de noves vivències, de gaudi i comprensió d'allò que va ser i d'allò que podria heretar-se, com a possibilitat de construir la memòria històrica. Com afirma Gadamer (1977), "la memoria tiene que ser formada" i només es pot aconseguir en relació amb l'altre, "sólo puede proceder de la vida social".

Per tant, quin lloc millor per a fer-ho que en aquell escenari on hem nascut i crescut, on s'han tingut les primeres experiències per desenvolupar el nostre llenguatge, eficaç eina que ens permet comprendre $\mathrm{i}$ comprendre'ns. Quan els avis narren les seves històries dels seus anys d'infantesa, als néts; quan el pare/mare explica com va arribar la seva família a la ciutat $o$ al poble; quan els germans grans conversen amb els petits al voltant de les aventures que van tenir quan eren nens, o de les dificultats que visqueren quan hi havia escassetat de treball. Tots aquests moments obren espais perquè la memòria es construeixi de múltiples formes, de manera que es pugui comprendre el present i es projecti el nostre futur aprenent de les experiències passades, evitant els errors comesos, valorant el sacrifici i l'esforç invertit.

La coexistència d'una o més generacions en la cultura familiar també permetria centrar l'atenció en la qualitat de les relacions que s'estableixen dins la família, en com els membres més joves es preparen per inserir- 


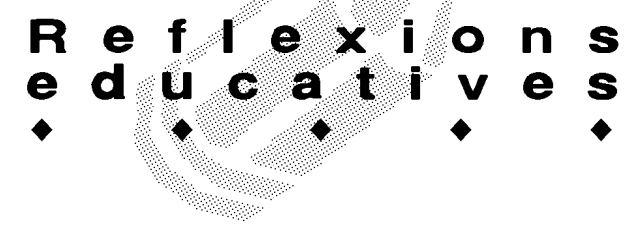

se en la societat, ja que la família, en donar vida a les noves generacions, també és responsable de crear les condicions perquè aquestes sobrevisquin en contextos sòcioculturals més optimitzadors, procurant, no només el seu "benestar", sinó també el seu "estar bé" (ALTAREJOS, 2004). És així com la cultura familiar es converteix en escenari fonamental per al desenvolupament de les noves generacions a l'integrar, dins la seva unitat, la diferència i la diversitat que afavoreix la transferència de les millors experiències, coneixements, tradicions, valors i actituds acumulats per les diferents generacions en l'esdevenir històric, com la més rica dot que es pot atorgar a les noves generacions.

\section{L'afecte com a motor dinamitzador}

Un nadó està totalment indefens. És dependent i vulnerable. El seu procés d'humanització comença amb els vincles i atencions que li ofereixen els seus progenitors, avis, etc. Quan aquestes atencions són de bona qualitat, dins d'una atmosfera estable, els efectes dins els processos adaptatius resulten molt positius. Quan el petit està famèlic, sol o incòmode, el seu plor pretén atreure una resposta de la persona que té cura d'ell per tal que li calmi la seva gana o soledat. Aquestes primeres interaccions, al nadó li ensenyaran a identificar-se amb un altre ésser, a sentir-se acollit, estimat. Aquesta relació-interacció de caràcter més aviat unilateral, gradualment l'introdueix al fenomen polièdric de l'amor. A mesura que el nen creix, l'entorn i les persones que l'envolten li ensenyaran el significat de l'amor de maneres diferents (forma de parlar, de jugar, d'aguantar-lo, netejar-lo, alimentar-lo...). Cada membre de la família només li ensenyarà el que ell sap sobre l'amor i, conseqüentment, el nen projectarà allò que de manera progressiva està aprenent.

A més a més de la cultura familiar, hi ha altres influències que ensenyen el que és l'amor. Una d'elles és la cultura de la societat en la qual es troba immersa la primera. Aquesta també ensenya a la família les seves respostes a l'amor, de manera que servirà per reforçar més o menys les accions del nen.

La paraula amor identifica l'afecte, la necessitat d'estar prop de l'altre, de l'acceptació incondicional del qui s'estima, del suport constant, de l'expressió dels sentiments més nobles que edifiquen la persona humana; per això ha de ser la saba que recorre tota la dinàmica que es gesta dins la cultura familiar, en les relacions entre pares i fills, en els integrants de la parella, entre els membres que estan presents en tota la seva estructura.

A la cultura familiar s'aprèn a rebre amor, però també s'aprèn a donar-lo als altres, a expressar-lo de formes diverses, a compartir i acceptar els altres. Hi ha un llenguatge afectiu que es construeix en la quotidianitat, amb les paraules, amb gestos o amb petits detalls (servir l'esmorzar amb alegria, preparar un plat preferit, sorprendre amb unes flors a l'ésser estimat, escriure-li una carta al fill, deixar un missatge a la porta de la nevera, enviar un missatge de mòbil, gaudir d'una bona lectura junts, felicitar algú pel bé que fa els treballs, expressar el bé que li escau un vestit nou, escriure un correu electrònic, abraçar, fer un petó, donar les gràcies, dialogar, somriure...). Aquestes expressions d'afecte mantenen viva la il.lusió per estar junts, per compartir el temps i l'espai amb la persona estimada, per aprendre a conviure en un ambient tranquil, agradable i que convidi sempre a retornar a casa, a voler estar al costat dels éssers estimats. Quan no experimentem algun d'aquests sentiments, caldrà estar alerta, ja que segurament hi haurà alguna situació que no encaixa o és a punt d'atrofiar el bon funcionament de la dinàmica familiar.

Quan l'ésser humà se sent estimat i acceptat dins d'una cultura familiar determinada, construeix una visió positiva de si mateix i del seu entorn, que l'ajudarà a enfortir l'autoestima, aprenent que la vida és una aventura que cal assumir amb entusiasme i entrega, en aquell encontre amb si mateix, amb l'altre i el seu entorn (món de l'alteralitat).

\section{Compromís estable entre els seus membres}

Comprometre's significa prendre part de la realitat, implicar-se en ella, procurar canviar les estructures negatives de la cultura familiar en la qual jo visc i transformar-la positivament. Però aquesta actitud ha de ser constant, sistemàtica, s'ha de mantenir al llarg del meu recorregut biogràfic dins d'aquella cultura pròxima que m'alberga. Per això emfasitzem el caràcter estable, perquè contràriament seria una manifestació superficial, espontània, passatgera, que lluny de garantir l'estabilitat del món familiar, propiciaria la inseguretat, el desequilibri i la incertesa.

Al llibre: Cien valores para una vida plena. La persona y su acción en el mundo, Torralba (2004) ens parla del compromís com una forma d'implicació en el món. Una persona compromesa és coherent amb les seves visions del món i els seus horitzons de sentit, elements bàsics de l'exemplaritat dels pares en les seves relacions paternofilials. Quan els progenitors compleixen la seva paraula i la seva forma d'actuació no contradiu les seves argumentacions, li ofereixen al seu fill una de les millors Iliçons de la vida: la confiança en els altres, la qual cosa li permet créixer enmig d'una certa seguretat i equilibri que les altres esferes socials, carregades pels vents de la postmodernitat, no li ofereixen. 


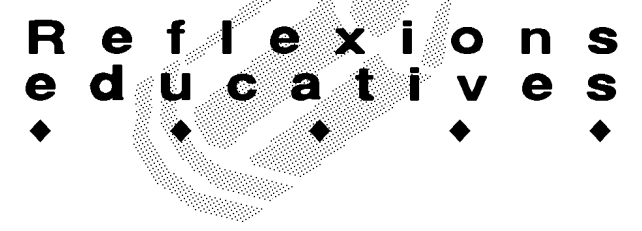

Per altra part, el compromís està íntimament relacionat amb la responsabilitat. Una persona responsable és capaç de comprometre's en el compliment de les tasques $\mathrm{i}$, quin millor escenari per a aquest tipus d'aprenentatge que la cultura familiar? Precisament Rosemond (1999) ens explica les raons per les quals els fills han de desenvolupar tasques domèstiques com un mitjà per créixer en responsabilitat i compromís. A continuació sintetitzem aquestes motivacions: 1) Fomentar les habilitats necessàries que els preparen per a la vida adulta, apreciant els esforços dels altres. 2) Actualitzar la participació en la família i reforçar els sentiments d'acceptació i seguretat. 3) Afavorir la satisfacció personal, la seva autoestima quan reconeixen que la seva contribució de temps i energia a la família es considera important. 4) Possibilitar la construcció d'un esperit cívic, on es busca contribuir al sistema abans que beneficiar-se d'ell. 5) Vincular els fills als valors familiars atès que les tasques domèstiques es converteixen en l'únic mitjà del qual disposen per contribuir tangiblement a la família.

Aquells petits als quals se'ls permet participar de forma habitual en les tasques domèstiques tenen més clars els valors dels seus pares, i això fa que tinguin més probabilitats que els assumeixin i que en tinguin una vivència pròpia, a partir del bon exemple dels seus progenitors.

En un apartat del llibre de Melich i Palou (2000), titulat: El compromís: Entre dir i fer hi ha poca distància, els autors argumenten que "El compromís sempre demana concreció, ser explicitat i vehiculat amb el testimoni", i arriben a aquesta afirmació després de descriure una trobada casual al mercat, d'una exalumna (amb dos fills) i la seva professora de química (que ja és àvia), a qui li expressava la seva admiració i gratitud pels coneixements que, amb gran sentit comú i afecte, aconseguí transmetre-li durant aquells anys. La professora, sorpresa per aquest gest, també li donà les gràcies per les paraules de reconeixement vers el seu treball. Sens dubte, el seu compromís amb l'educació li permetia viure una bonica experiència que quedava enregistrada a la seva memòria (i a la de la seva exalumna) per sempre.

De la mateixa forma que a aquesta experiència anecdòtica entre una professora i la seva alumna, els pares/mares, al costat dels seus fills, podran seguir construint moltes altres històries dignes de ser narrades. El compromís dels pares per donar suport als seus fills a l'escola, el compromís per oferir-los el major ben-estar i l'estar-bé a casa, el compromís per assistir-los quan tenen alguna dificultat, el compromís per iniciar-los en el descobriment del món...
Aquest compromís ens converteix en "miralls on els altres puguin reflectir-se" i apropiar-se -conscientment o inconscientment- d'una forma d'entendre el món i d'estar-hi. Com molt bé expressa Van Manen (1998): "...todos somos profesores en la medida en que enseñamos a los niños y a los jóvenes, a través de nosotros mismos, de nuestras formas culturales de vida y a través de nuestra vidas individuales, cómo se debe vivir".

\section{Referències bibliogràfiques}

ALTAREJOS, F. i altres. Familia, valores y educación. Segunda ponencia. XXIII Seminario Interuniversitario de Teoría de la Educación Familia, Educación y Sociedad civil. Universidad de Santiago de Compostela, Lugo. 2004.

BELSKY, J. Chile maltreatment: An ecological integration. «American Psychologist», 35 (1980) 320-335.

BERTALANFFY, L.V. System theory: Foundations, development, applications. Edit. Braziller. Nueva York. 1968.

DELORS, J. La educación encierra un tesoro. Edit. Santillana/Unesco. Madrid. 1996.

GADAMER, H. Verdad y método. Edit. Sígueme. Salamanca. 1977.

LERNER, R.M. Children and adolescents as producers of their own development. «Development Review», 2 (1982) 342-370.

LEWIS, M. i BROOKS-GUNN, J. Social cognition and the acquisition of self. Edit. Plenum. New York. 1979.

LUJÁN, M. L., VANDEMEULEBROECKE, L. i COLPIN, H. Pedagogía familiar. Aportes desde la teoría y la investigación. Edit. Trilce. Uruguay. 2001.

MÈLICH, J. i PALOU, J. La veu de l'altre. Reflexions $i$ experiències per educar en valors ètics. Universitat Autònoma de Barcelona. Barcelona. 2000.

MUSITU, G. i HERRERO, J. La familia: formas y funciones. En G. Musitu y P. Allat (eds.) Psicosociología de la familia (pp.17-46). Edit. Albatros. Valencia. 1994.

RODRIGO, M. J. i PALACIOS, J. Familia y desarrollo humano. Alianza Editorial. Madrid. 1998.

ROSEMOND, J. Cómo tener hijos felices y adaptados. Edit. Médici. Barcelona. 1999.

SAMEROFF, A. J. Development systems: Contexts and evolution. En W.Kessen (ed.) History, theory and methods, volumen I, de P.H. Mussen (ed.) Handbook of child psychology (pp.237-294). Edit. Wiley. Nueva York. 1983.

SAMEROFF, A. J. i CHANDLER, M. J. Reproductive risk and the continuum of caretaking casualty. En: F.G. Horowitz (ed). Review of child development research, vol.4. Edit. University of Chicago Press. Chicago. 1975.

THOMAS,A. i CHESS, S. Temperament and development. Edit. Brunner-Mazel. Nueva York. 1987.

TORRALBA, F. Cien valores para una vida plena. La persona y su acción en el mundo. Edit. Milenio. Lleida. 2004.

VAN MANEN, M. El tacto en la enseñanza. El significado en la enseñanza. Edit. Paidós. Barcelona. 1998. 